\title{
ANALISIS PENGARUH KOMPONEN TEKNOLOGI TERHADAP DAYA SAING UKM INDUSTRI GENTENG
}

\author{
Dwi Sulisworo, Siti Mahsanah Budijati dan Mandasari Wahyu Hutami \\ Jurusan Teknik Industri \\ Universitas Ahmad Dahlan \\ Email :
}

\begin{abstract}
ABSTRAK
Sentra industri genteng di daerah Sokka Kebumen yang dikelola oleh UKM, merupakan salah sentra industri Syang menjadi andalan Kabupaten Kebumen pada khususnya. Sentra industri ini diharapkan dapat berkembang dan menjadi percontohan UKM dari daerah lain. Penelitian ini ditujukan pada pengukuran kemampuan internal dalam melakukan proses transformasi (proses produksi) dengan dukungan empat komponen teknologi. Diharapkan informasi yang menggambarkan kemampuan teknologi perusahaan genteng dapat diungkap untuk meningkatkan daya saing perusahaan. Selain perusaahaan dapat melakukan identifikasi teknologi yang relevan untuk digunakan.

Teknologi yang dijabarkan dalam penelitian sebagai fasilitas transformasi dalam proses produksi, terdiri dari 4 komponen teknologi, yaitu fasilitas fisik (technoware), sumber daya manusia (humanware), informasi (infoware) dan organisasi perusahaan (orgaware) atau yang biasa disebut dengan Teknometrik. Data yang diambil berasal dari kuesionair teknometrik dan kuisioner AHP. Hasil penelitian menunjukkan untuk perusahaan dengan jenis usaha rumah tangga terdapat 4 perusahaan dan mempunyai nilai TCC yang sama yaitu sebesar 0.16 dengan perincian Technoware berkisar antara 0.22 sampai 0.23, Humanware bernilai sama yaitu sebesar 0.14, Infoware berkisar antara 0.13 sampai 0.14 dan Orgaware berkisar antara 0.16 sampai 0.17. Untuk perusahaan dengan jenis usaha UD berjumlah 16 perusahaan dan mempunyai nilai TCC berkisar antara 0.15 sampai 0.19 dengan perincian Technoware berkisar antara 0.21 sampai 0.3, Humanware berkisar antara 0.14 sampai 0.15 , Infoware berkisar antara 0.12 sampai 0.18 dan Orgaware berkisar antara 0.16 sampai $0.17 . .2$
\end{abstract}

\section{Kata Kunci: teknometrik, kontribusi teknologi, analisis hirarki}

\section{PENDAHULUAN}

Teknologi sangat berperan dalam menciptakan keunggulan bersaing suatu perusahaan. Teknologi telah banyak diaplikasikan sebagai variabel yang strategis untuk mengakselarasi pertumbuhan ekonomi dan pertumbuhan produktivitas. Beberapa perusahaan besar sangat memperhatikan teknologi yang dipergunakan melalui assessment teknologi untuk dijadikan dasar penentuan kebijakan investasi teknologi baru. Hal ini relatif jarang digunakan pada perusahaan kecil menengah (UKM). Pada UKM cenderung hanya berusaha agar proses produksi berjalan lancar sesuai dengan prosedur yang telah ditetapkan atau sesuai dengan instruksi pimpinan bagian tertentu. Dampak aktivitas ini adalah perbedaan kontribusi teknologi yang digunakan antar perusahaan sejenis atau belum ada pemerataan teknologi; selain juga cara kerja atau proses penyelesaian produk yang bervariasi.

Teknologi merupakan salah satu pendukung perkembangan perusahaan yang sangat penting dan perlu diperhatikan. Perkembangan kontribusi teknologi yang digunakan perusahaan-perusahaan yang bergerak dalam usaha sejenis akan berakibat pada variasi cara kerja atau proses penyelesaian produk, kemampuan sumber daya, akses informasi, dan sistem organisasi yang diterapkan. Perusahaan yang mampu mengikuti perkembangan teknologi secara tidak langsung akan dapat meningkatkan daya saing.

Untuk mengembangkan strategi operasional, identifikasi posisi perusahaan dalam penggunaan teknologi, salah satunya dengan pendekatan teknometrik, dapat digunakan sebagai dasar peningkatan daya saing pada pasar yang sejenis. Teknometrik adalah salah satu metode pengukuran kontribusi komponen teknologi yang mencakup Technoware, Humanware, Infoware, dan Orgawere.

\section{Landasan Teori}

Kata "Technometric" telah banyak digunakan dalam banyak analisis pada saat ini untuk menunjukkan pengukuran aspek-aspek teknologi. Keempat komponen dasar teknologi (technoware, 
humanware, inforware, dan organware) mengubah input menjadi output yang mempunyai variasi dan tingkat kompleksitas yang berbeda-beda. Keempat komponen dasar tersebut saling melengkapi satu dengan lain dan dibutuhkan cara simulasi di setiap proses transformasi.

Technoware adalah inti proses transformasi yang dibagi menjadi dua yaitu Hardware dan Software. Technoware ini dikembangkan, diinstal, dan dibangun oleh Humanware dengan menggunakan Infoware yang telah terkumpul sebelumnya. Technoware tidak akan mampu bekerja sendiri dan tidak akan berguna jika humanware tidak mempergunakannya. Humanware mempunyai peran kunci proses transformasi. Humanware menyebabkan technoware menjadi lebih produktif. Namun demikian, sesuatu yang akan dikerjakan tergantung pada infoware yang tersedia sebagai representasi pengetahuan yang berkembang. Orgaware mengkoordinasi infoware, humanware dan technoware dalam suatu proses transformasi agar proses berlangsung efisien.

Jika proses transformasi dicermati maka akan terasa adanya kenaikan derajat sophistication masing-masing komponen teknologi. Adanya kenaikan sophistication technoware yang dipakai akan menuntut humanware yang mempunyai kemampuan untuk mengoperasikan technoware tersebut. Sedangkan kenaikan sophistication technoware dan humanware menuntut adanya infoware yang memadai. Terakhir, diperlukan orgaware yang mampu mengintegrasikan secara efektif ketiga komponen tersebut melalui berbagai fungsi manajemen yang ada.

Model teknometrik berfungsi untuk mengukur kontribusi gabungan keempat komponen teknologi terhadap kompleksitas teknologi. Hasil yang diperoleh dari penggunaan model ini adalah tingkat koefisien kontribusi teknologi atau Technology Contribution Coefficient (TCC). Koefisien kontribusi teknologi (TCC) dapat dinyatakan sebagai berikut:

$$
T C C=T^{\mathrm{b} t} * H^{\mathrm{b} h} * I^{\mathrm{b} i} * O^{\mathrm{bo}}
$$

Komponen T, H, I, dan O menyatakan kontribusi individu yang diberikan oleh technoware, humanware, infoware, dan orgaware. Fungsi perkalian Technology Contribution Coefficient (TCC) dapat dijelaskan sebagai berikut: fungsi Technology Contribution Coefficient (TCC) menunjukkan $\mathrm{T}, \mathrm{H}$, I, dan $\mathrm{O}$ tidak sama dengan nol. Hal ini disebabkan karena semua proses mendayagunakan semua komponen teknologi tersebut.

Langkah yang dilakukan dalam menghitung TCC adalah sebagai berikut:

1. Memperkirakan derajat sophistication suatu komponen teknologi.

Tingkat kecanggihan komponen teknologi ditentukan dengan memberikan skor skala sembilan, tepatnya berkisar antara 1 sampai 9 . Hasil estimasi ini akan memberikan batas atas (Upper Limit, UL) dan batas bawah (Lower Limit, LL)

2. Menilai State-of-the-art

Pembobotan pada State-of-the-art ini berkisar antara 0 sampai 1 yang bertujuan normalisasi penilaian dan sekaligus mengimplikasikan bahwa kriteria yang digunakan mempunyai bobot yang sama.

3. Menentukan kontribusi komponen teknologi atau normalisasi

Berdasarkan pada pengetahuan tentang batas level sophistication dan rating state of the art pada langkah ketiga ini data kontribusi komponen dihitung dengan menggunakan persamaan

$$
\boldsymbol{T}=\frac{1}{9}\left[\mathbb{L}_{i}+\mathbb{S}_{i}\left(\mathbb{U}_{i}-\mathbb{L}_{i}\right)\right]
$$

4. Intensitas kontribusi komponen

Intensitas kontribusi komponen diestimasi dengan pendekatan pairwaise comparison matrix.

5. Menghitung persamaan Technology Contribution Coefficien (TCC)

TCC perusahaan menunjukkan kontribusi teknologi untuk keseluruhan operasi transformasi. TCC dihitung dengan nilai $\mathrm{T}, \mathrm{H}$, I, $O$ dan $\beta$ yang telah diperoleh persamaan (1). Oleh karena nilai $0<\mathrm{T}, \mathrm{H}, \mathrm{I}, \mathrm{O}<1$ dan $\mathrm{b}_{t}+\mathrm{b}_{h}+\mathrm{b}_{i}+\mathrm{b}_{o}=1$

(setelah dinormalisasikan), maka nilai maksimum TCC adalah sama dengan satu.

\section{METODE}

Populasi data ini adalah industri kecil genteng yang ada sentra industri yang diteliti berjumlah 20 perusahaan(baikyangindistrirumah tanggamaupun 
Usaha Dagang). Semua UKM ini dijadikan sampel dalam penelitian. Metode yang digunakan untuk pengumpulan data adalah kuesionair, observasi, dan wawancara. Sehingga diharapkan, dengan melakukan penelitian langsung di perusahaan, dapat mendeskripsikan keadaan nyata penerapan komponen teknologi. Metode pengolahan data untuk menentukan kontribusi kandungan teknologi (TCC) ditunjukkan pada gambar 1 .

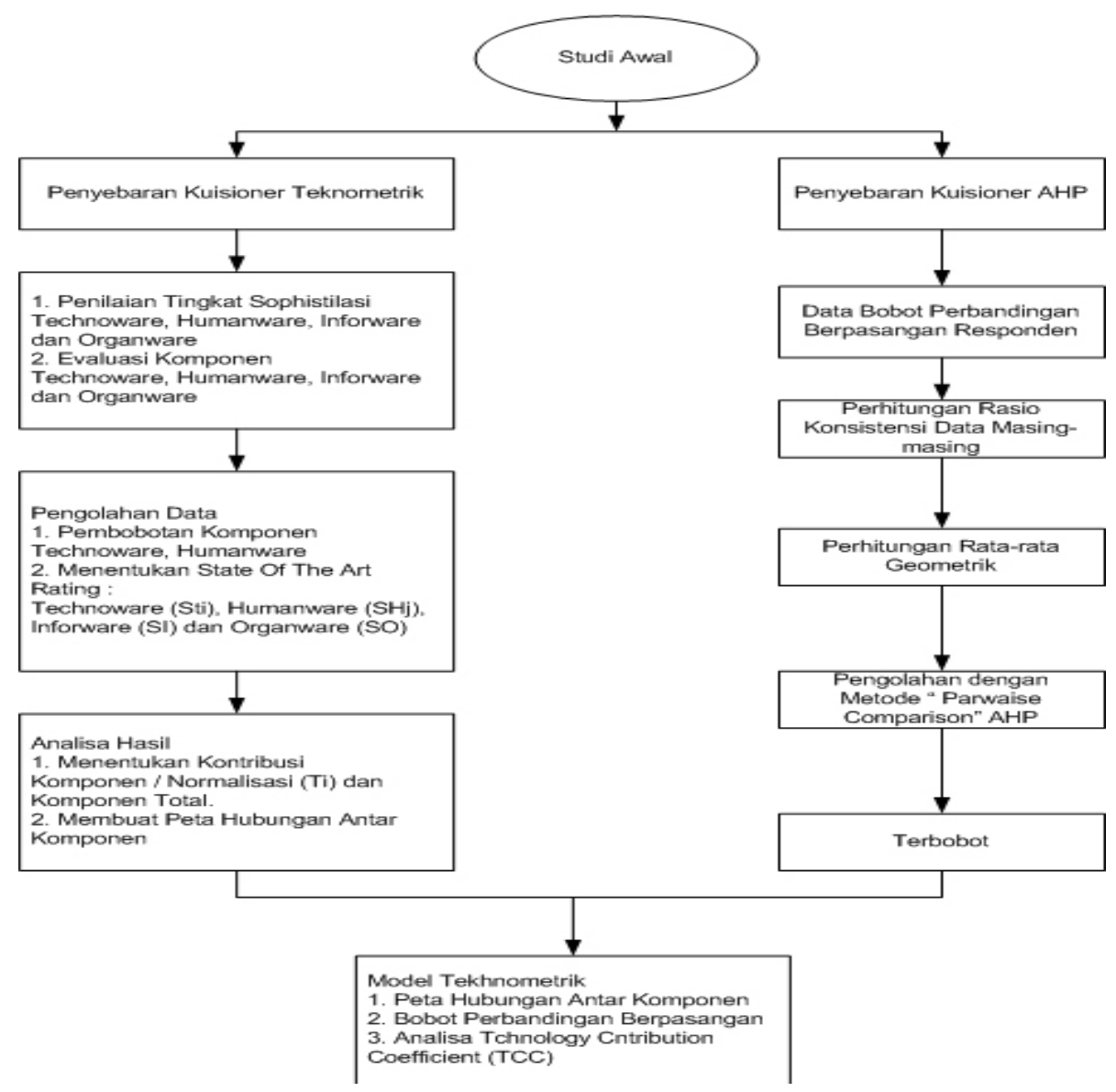

\section{HASIL DAN PEMBAHASAN}

Gambar 1 Metode Pengolahan Data

Berdasarkan pada pengolahan data, diperoleh hasil Consitency ratio (CR) semua perusahaan kurang dari 0.1 atau $10 \%$. Langkah berikutnya adalah mencari "Rata-rata geometrik" AHP. Hasil keseluruhan untuk semua komponen ditunjukkan pada tabel 1.

\section{Tabel 1. Rata-rata geometrik THIO}

\begin{tabular}{|l|c|c|c|c|}
\hline & $\begin{array}{c}\text { Techno- } \\
\text { ware }\end{array}$ & $\begin{array}{c}\text { Human- } \\
\text { ware }\end{array}$ & $\begin{array}{c}\text { Info- } \\
\text { ware }\end{array}$ & $\begin{array}{c}\text { Or- } \\
\text { gaware }\end{array}$ \\
\hline Technoware & 1 & 0.94 & 0.88 & $\mathbf{0 . 8 8}$ \\
\hline Humanware & 1.05 & 1 & 0.87 & $\mathbf{0 . 9 5}$ \\
\hline Infoware & 1.16 & 1.21 & 1 & $\mathbf{1 . 1 2}$ \\
\hline Orgaware & 1.1 & 1.03 & 0.9 & $\mathbf{1}$ \\
\hline \hline & $\mathbf{4 . 3 1}$ & $\mathbf{4 . 2 1}$ & $\mathbf{3 . 6 5}$ & $\mathbf{3 . 9 5}$ \\
\hline
\end{tabular}

Dari pengolahan data, nilai beta $(\beta)$ secara langsung dapat diperoleh dengan menjumlahkan dari tiap komponen technoware, humanware, infoware dan orgaware, hasil rata-rata perhitungan geometrik kemudian dibagi empat. Langkah awal yang harus dilakukan adalah menghitung priority weight berdasar pada tabel THIO rata-rata geometrik. Adapun hasilnya adalah seperti tabel 2. 
Tabel 2. Priory Weight hasil rata-rata geometrik

\begin{tabular}{|l|c|c|c|c|c|c|}
\hline & Technoware & Humanware & Infoware & Orgaware & $\sum$ THIO & $\beta$ \\
\hline Technoware & 0.23 & 0.22 & 0.24 & 0.22 & 0.91 & 0.23 \\
\hline Humanware & 0.24 & 0.24 & 0.24 & 0.24 & 0.96 & 0.24 \\
\hline Infoware & 0.27 & 0.29 & 0.27 & 0.28 & 1.11 & 0.28 \\
\hline Orgaware & 0.26 & 0.25 & 0.25 & 0.26 & 1.02 & 0.25 \\
\hline Jumlah & 1.00 & 1.00 & 1.00 & 1.00 & & 1.00 \\
\hline
\end{tabular}

Dengan nilai beta yang telah diperoleh, TCC dapat dihitung untuk setiap perusahaan. Hasil perhitungan ini ditunjukkan oleh tabel 3. Dari tabel 3 terlihat komponen technoware memberikan nilai kontribusi tertinggi di hampir semua perusahaan. Nilai komponen Technoware berkisar antara 0,21 sampai 0,30 . Juga dapat dilihat bahwa terdapat 2 perusahaan, yaitu perusahaan genteng $\mathrm{S}$ dan $\mathrm{T}$ yang tertinggi dibanding yang lain dengan nilai kontribusi masing - masing 0,30 . Hal ini menunjukkan bahwa meski komponen technoware dua perusahaan tersebut tertinggi dibanding perusahaan di sentra tersebut, namun masih jauh dari memadai karena nilainya jauh dari 1. Nilai kontribusi technoware yang lebih tinggi dibanding nilai kontribusi komponen yang lain, dapat disebabkan karena teknologi yang diterapkan relatif sama atau hampir semuanya sama baik dari segi alat yang digunakan sampai dengan proses pembuatan genteng.

Tabel 3. Kontribusi Kandungan Teknologi

\begin{tabular}{|c|c|c|c|c|c|c|c|c|}
\hline \multirow{3}{*}{ Perusahaan } & \multicolumn{7}{|c|}{ Kontribusi Total } & \multirow{3}{*}{$\mathrm{TCC}$} \\
\hline & $\mathrm{T}$ & \multicolumn{2}{|c|}{$\mathrm{H}$} & \multicolumn{2}{|c|}{ I } & \multicolumn{2}{|c|}{$\mathrm{O}$} & \\
\hline & $\beta=0.2$ & $\beta=$ & .24 & $\beta=$ & .28 & $\beta=$ & .25 & \\
\hline $\mathbf{A}$ & 0.23 & 0. & 4 & 0. & 3 & 0. & 6 & 0.16 \\
\hline B & 0.24 & 0. & 4 & 0 & 3 & 0. & 8 & 0.17 \\
\hline & 0.24 & 0. & 4 & 0. & 4 & 0. & 7 & 0.16 \\
\hline $\mathrm{D}$ & 0.25 & 0. & 4 & 0 & 4 & 0. & 6 & 0.17 \\
\hline E & 0.23 & 0. & 4 & 0. & 3 & 0 . & 6 & 0.16 \\
\hline$\overline{\mathbf{F}}$ & 0.25 & 0. & 4 & 0. & 4 & 0. & 6 & 0.17 \\
\hline $\mathrm{G}$ & 0.26 & 0. & 4 & 0. & 6 & 0. & 6 & 0.17 \\
\hline Ḧ & 0.23 & 0. & 4 & 0. & 3 & 0. & 7 & 0.16 \\
\hline & 0.27 & 0. & 4 & 0 & 4 & 0. & 6 & 0.17 \\
\hline & 0 & 0. & 4 & 0 & 3 & 0. & 6 & 0.16 \\
\hline $\bar{K}$ & 0.23 & 0. & 4 & 0. & 3 & 0. & 6 & 0.16 \\
\hline L & 0.21 & 0. & 4 & 0. & 2 & 0. & 6 & 0.15 \\
\hline V & 0.23 & 0. & 4 & 0. & 3 & 0 & 6 & 0.16 \\
\hline $\mathbf{N}$ & 0.23 & 0. & 4 & 0. & 4 & 0. & 6 & 0.16 \\
\hline 0 & 0.24 & 0. & 4 & 0 & 2 & 0 & 5 & 0.15 \\
\hline P & 0.24 & 0. & 4 & 0. & 3 & 0. & 6 & 0.16 \\
\hline 0 & 0.25 & 0. & 5 & 0. & 7 & 0. & 7 & 0.18 \\
\hline $\mathbf{R}$ & 0.25 & 0. & 4 & 0 & 5 & 0. & $\frac{1}{6}$ & 0.17 \\
\hline$S$ & 0.3 & 0. & 5 & 0 . & 4 & 0. & 7 & 0.18 \\
\hline & 0.3 & 0. & 5 & 0. & 8 & 0. & 7 & 0.19 \\
\hline
\end{tabular}

Dari tabel 3 dapat dilihat juga bahwa komponen Humanware dan infoware cenderung memberikan kontribusi yang lebih kecil. Nilai humanware tiap perusahaan yang diteliti berkisar antara 0,14 dan 0,15. Nilai humanware kecil, sebab pada dasarnya kemampuan tenaga kerja yang ada masih sebatas mengoperasikan alat, yang merupakan level terendah penilaian kemampuan tenaga kerja (humanware). Dengan demikian komponen humanware ini perlu mendapat perhatian untuk 20 ditingkatkan agar dapat memberikan kontribusi yang lebih tinggi pada proses transformasi.

Nilai inforware tiap perusahaan berkisar antara $0,12-0,18$. Nilai infoware kecil menunjukkan bahwa sistem informasi yang ada di setiap perusahaan masih bersifat manual, bahkan seringkali tidak terdapat sarana untuk sistem informasi antar departemen ataupun dengan institusi lain. Penyebaran informasi dilakukan secara lisan, atau bahkan hanya berdasarkan 
kebiasaan sehari-hari dalam berproduksi, sehingga kemampuan komponen infoware ini merupakan kemampuan terendah sehingga perlu pembinaan untuk pengembangan sistem informasi yang lebih baik.

Untuk kemampuan orgaware tiap perusahaan yang diteliti mempunyai nilai berkisar antara 0,16 - 0,18. Kemampuan orgaware cenderung sama diantara perusahaan yang ada, sebab karena pengelolaan organisasi pada perusahaan genteng telah cukup standar untuk perusahaan sekelas UKM. Kemampuan teknis berproduksi (technoware) secara riil memang masih rendah, karena sebagian besar peralatan yang ada untuk proses produksi merupakan fasilitas manual, dan hal ini merupakan level terendah bagi penilaian kemampuan teknologi produksi. Dengan demikian perlu dikembangkan inovasi-inovasi teknologi produksi dan mekanisme sistem produksi.

Telah diketahui bahwa nilai kontribusi yang baik apabila mendekati nilai 1. Dari tabel menunjukkan bahwa nilai kontribusi masing-masing komponen baik technoware, humanware, infoware dan orgaware tidak ada yang mencapai nilai 0,5 . Berarti kemampuan semua komponen teknologi tersebut sangat rendah sehingga masih perlu pembinaan insentif untuk meningkatkan kemampuan semua komponen. Hasil akhir yang berupa nilai TCC pada tabel menunjukkan bahwa terdapat 1 perusahaan (perusahaan $\mathrm{T}$ ) yang mempunyai nilai TCC terbesar $(0,19)$. Namun demikian nilai tersebut sangat rendah, karena nilai TCC ini menunjukkan ukuran kontribusi bersama dari keempat komponen teknologi terhadap kepuasan penggunaan teknologi secara keseluruhan pada fasilitas transformasi. Dengan nilai tertinggi 0,19, berarti tingkat kepuasan penggunaan teknologi secara keseluruhan pada fasilitas transformasi, pada perusahaan yang paling unggul pun hanya sebesar $19 \%$.

\section{KESIMPULAN}

Berdasarkan analisis TCC pada sentra industri genteng(UKM) dapat diambil beberapa kesimpulan berikut:

1. Nilai kontribusi masing-masing komponen adalah komponen Technoware berkisar antara 0,21 sampai 0,30, komponen Humanware berkisar antara 0,14 sampai 0,15, komponen Infoware berkisar antara 0,12 sampai 0,18 dan komponen Orgaware berkisar antara 0,16 sampai 0,18; dan nilai koefisien kontribusi teknologi (TCC) berkisar antara 0,15 sampai 0,19 .

2. Komponen Technoware merupakan komponenyangmemberikannilaikontribusi tertinggi pada sebagian perusahaan. Sedangkan komponen Humanware dan Infoware cenderung memberikan nilai kontribusi yang kecil, dan komponen Orgaware cenderung rendah.

3. Kemampuan teknologi pada semua perusahaan yang masih rendah menunjukkan ukuran kontribusi bersama keempat komponen teknologi terhadap kepuasan penggunaan teknologi secara keseluruhan pada fasilitas transformasi baru berkisar antara $15 \%$ sampai $19 \%$.

\section{DAFTAR PUSTAKA}

Anonim, 1989, A Frame For TechnologyBased Development Technology Contents Assessment, Technology Atlas Project, Volume II

Mahsanah Siti, Tri Joko Wibowo, 2004, Assesment Kandungan teknologi Sebagai Usaha Pemetaan Posisi teknologi Pada Industri Kecil Dan Menengah, Program Hibah Kompetisi A-1, Penelitian Dosen, Teknik Industri, Universitas Ahmad Dahlan Yogyakarta.

Jerusalem M.A., 2002 Technology Atlas Project Metod dan Manajemen Peningkatan Mutu Berbasis Sekolah sebagai Alat Penjamin Mutu Jasa Pendidikan, Fakultas Teknik UNY.

Saaty, T.L,1993, Proses Hirarki Analitik untuk Pengambilan keputusan dalam Situasi yang Kompleks. 